\title{
Arquitectura e innovación. Las claves de la obra de Antonio Lamela y Estudio Lamela. Su aportación a los siglos XX y XXI
}

\section{The keys to Antonio Lamela and Estudio Lamela works and its contribution to the XX and XXI centuries}

$\underline{\text { C. Lamela }}^{(*)}$

\section{RESUMEN}

En el artículo se realiza un repaso de la trayectoria conjunta de mi padre, el Arquitecto Antonio Lamela, y de Estudio Lamela. Se señala la relación con la revista Informes, imprescindible referente y a veces único vehículo de difusión de la Arquitectura y la construcción en España. La relación con la revista ha sido estrecha y muy productiva.

Se realiza un recorrido desde la primera época del Estudio, con un protagonismo más personal de mi padre, hasta el periodo del acuñamiento del nombre "Estudio Lamela" para transmitir un concepto de empresa multidisciplinar y trabajo en equipo, una vez sumado al equipo mi tío Amador Lamela.

He intentado transmitir también mi visión personal a raíz de incorporarme a la Oficina y dirigir el desarrollo de obras importantes de esos momentos, como la ampliación del Estadio Santiago Bernabéu o la Terminal T4. También establecemos una reflexión sobre nuestro proceso de internacionalización.

Palabras clave: Antonio Lamela; Estudio Lamela; Informes de la Construcción; Arquitectura.

\section{ABSTRACT}

This paper makes a review of the joint trajectory of my father, the Architect Antonio Lamela, and "Estudio Lamela".

The relationship with the journal "Informes", essential reference and sometimes only vehicle of diffusion of Architecture and construction in Spain, is pointed out. The relationship with the journal has been close and very productive.

A timeline is made from the first moments of the office, with a more personal role of my father, until the period when its name changed to "Estudio Lamela" to convey a concept of multidisciplinary company and teamwork, once added to the team my uncle Amador Lamela.

I have also tried to give my personal vision as a result of joining the Office and directing the development of important works of those moments, such as the expansion of the Santiago Bernabéu Stadium or Terminal T4. We also establish a reflection on our internationalization process.

Keywords: Antonio Lamela; Estudio Lamela; Informes de la Construcción; Architecture.

(*) Arquitecto. Director Ejecutivo Estudio Lamela.

Persona de contacto/Corresponding author: clamela@lamela.com (C. Lamela).

ORCID: https://orcid.org/oooo-0002-4908-2049 (C. Lamela).

Cómo citar este artículo/Citation: C. Lamela (2019). Arquitectura e innovación. Las claves de la obra de Antonio Lamela y Estudio Lamela. Su aportación a los siglos XX y XXI. Informes de la Construcción, 71(553): e277. https://doi.org/10.3989/ic.67481

Copyright: (c) 2019 CSIC. Este es un artículo de acceso abierto distribuido bajo los términos de la licencia de uso y distribución Creative Commons Reconocimiento 4.0 Internacional (CC BY 4.0). 


\section{O. PREÁMBULO}

Con gran ilusión recibí de mi querida amiga Pepa Cassinello la invitación a sumar mis palabras al 70 aniversario de la para mi entrañable publicación "Informes de la Construcción". Independientemente de la íntima amistad entre nuestros padres, Fernando y Antonio, compañeros de curso, la relación de nuestras familias con la revista ha sido muy estrecha a nivel profesional. Reciente está aún el precioso artículo que Pepa Cassinello le dedicó a mi padre con motivo de su fallecimiento el pasado año (1).

\section{LA REVISTA INFORMES DE LA CONSTRUCCIÓN}

La Arquitectura, en su versión más técnica, y la Ingeniería Estructural difícilmente pueden entenderse en España sin la visión poliédrica y autorizada de Informes de la Construcción (IdC), desde su primer número hasta el último. Tribuna técnica y divulgativa, además de foro de investigación, de tantos proyectos y cuestiones de interés en nuestra querida profesión.

La revista IdC ha desempeñado también un papel fundamental en la propia transformación de la Arquitectura y la Ingeniería españolas (2). Su labor de difusión, recogiendo lo mejor de ambas disciplinas durante 70 años de dos siglos distintos, le confiere el papel de documento histórico de excepción, con el valor añadido de su interés por difundir las realizaciones de fuera de nuestras fronteras.

Estudio Lamela quiere mostrar su reconocimiento a esa labor compartiendo, de nuevo, unas páginas de la revista.

\section{ANTONIO LAMELA, ESTUDIO LAMELA E IDC}

Antonio Lamela estableció un estrecho contacto profesional con el Instituto Técnico de la Construcción y del Cemento, dirigido por Eduardo Torroja - actualmente Instituto de Ciencias de la Construcción Eduardo Torroja (IETcc)-, materializado en algunos artículos de su autoría y otros relativos a muchas de sus obras. Su identificación con el espíritu de rigor científico y técnico de la publicación le llevaron a participar en la revista siempre que pudo, por su compromiso común con un modo de entender la arquitectura desde un punto de vista multidisciplinar, concediendo especial importancia a factores tan decisivos como la industrialización, la tecnificación o los nuevos materiales, sin olvidar otros aspectos como los medioambientales y, en definitiva, sociales.

\section{LA INNOVACIÓN EN LA OBRA DE ANTONIO LAMELA Y ESTUDIO LAMELA}

La trayectoria de Estudio Lamela se puede explicar considerando varios ciclos: el de la obra individual de Antonio Lamela y el del Estudio constituido a partir de los años 70.

La obra de A L en exclusiva es la comprendida en los primeros quince años de su trayectoria profesional, entre 1954 en que obtiene el título de Arquitecto y 1970, cuando se incorpora su hermano Amador. En ese momento se acuña el término "E L" para transmitir la filosofía de un equipo, una organización, la empresa en la que ya se había convertido el pequeño Estudio inicial, que nace como un ente casi unipersonal y que ya a comienzos de los años sesenta era el más grande de la capital.

En 1970 el Estudio se encuentra en su cénit, con su nueva sede de O’Donnell 34, inaugurada en 1966 (3) (Figura 1), a

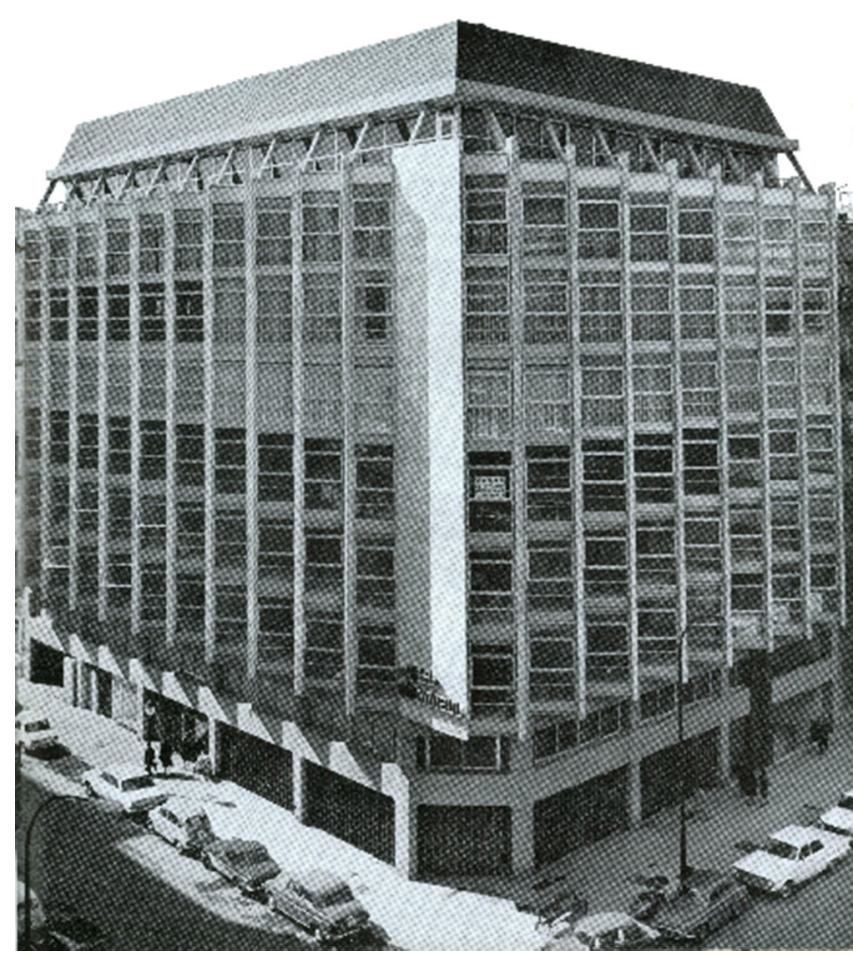

Figura 1. Sede del estudio en O’Donnell 34.

pleno rendimiento y cuenta con cincuenta profesionales de diferentes nacionalidades y disciplinas.

La innovación en la Arquitectura fue la base de su crecimiento, con propuestas iniciales verdaderamente audaces como el edificio de viviendas y despachos profesionales de O'Donnell 33 que, entre otras cosas, fue el primer edificio residencial de Madrid con clima artificial central, diseño de iluminación exterior, recogida centralizada de basuras, aseos interiores ventilados con shunts, tabiques móviles, etc.

A E L se debe también el primer motel de carretera de España, "El Hidalgo" (4), en Valdepeñas (Figura 2); los primeros apartoteles de costa,; el Complejo Galaxia (5), como la primera manzana con un concepto integral en su diseño formal y funcional, con diferentes niveles peatonales y un novedoso tratamiento del hormigón visto; el Hotel Meliá Madrid, primer gran hotel moderno de viajeros; El Barrio de San Ignacio de Loyola, ejemplo de un nuevo urbanismo integrador y verde con unas dotaciones y equipamientos inusuales para su época; los edificios con fachadas suspendidas y aplacados ligeros; los portales mixtos, con accesos diferenciados para vehículos y personas; la gran diafanidad de las plantas bajas y la integración de éstas en la urbe o en la naturaleza, como en el conjunto Roca Marina (Figura 3), en Mallorca (6), etc.; y desde luego, en TORRES COLÓN, como la obra cumbre que resume las "claves" de la arquitectura de Antonio Lamela.

\section{Las "claves" de la arquitectura de Antonio Lamela}

De forma muy breve, y como resumen, podrían enunciarse así:

- Su forma holista de enfocar los proyectos.

- La inserción de los edificios en el medio urbano: superación de los modelos del XIX, tanto entre medianeras (O’Donnell 33); como exentos (Torres Colón). 


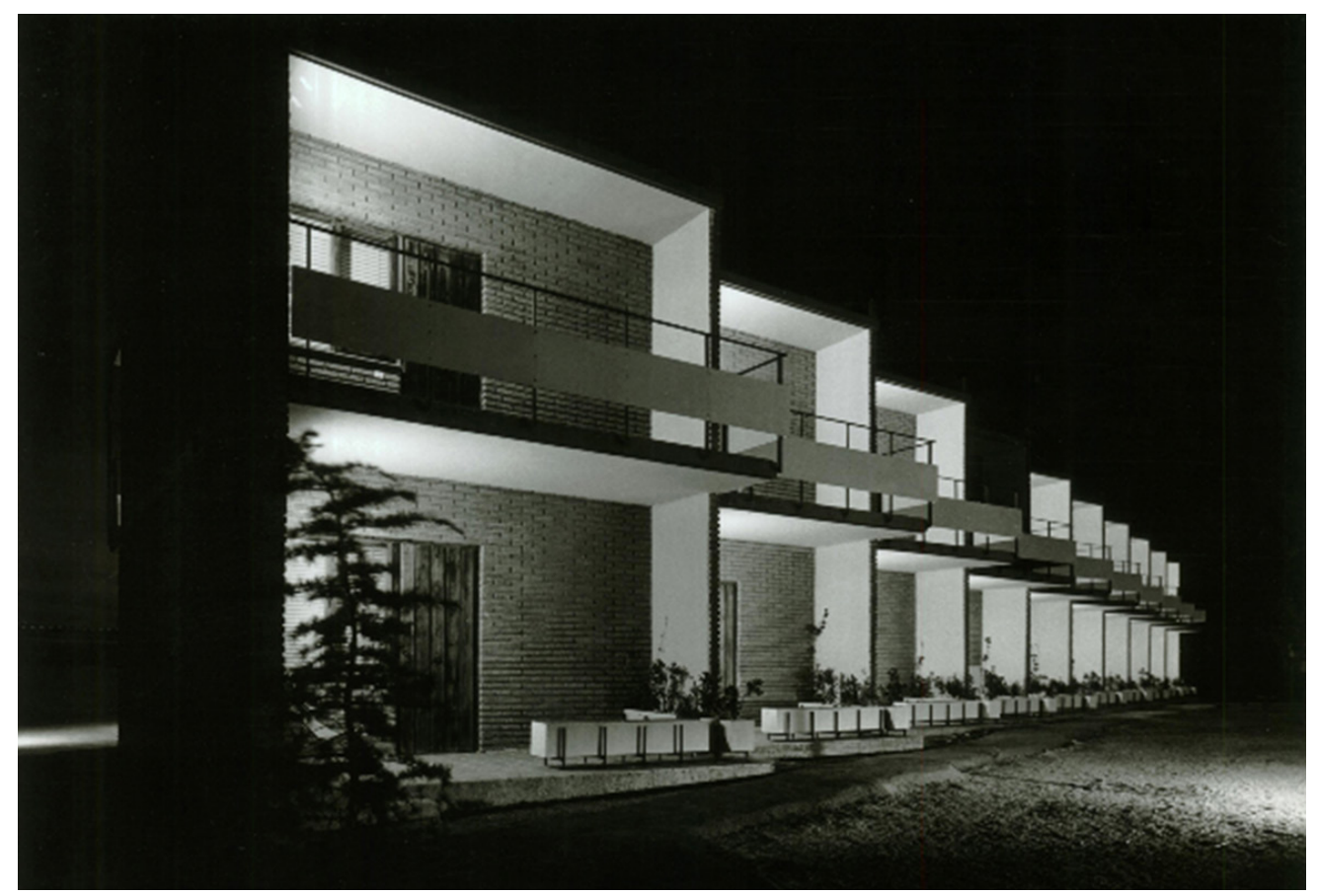

Figura 2. Motel el Hidalgo.

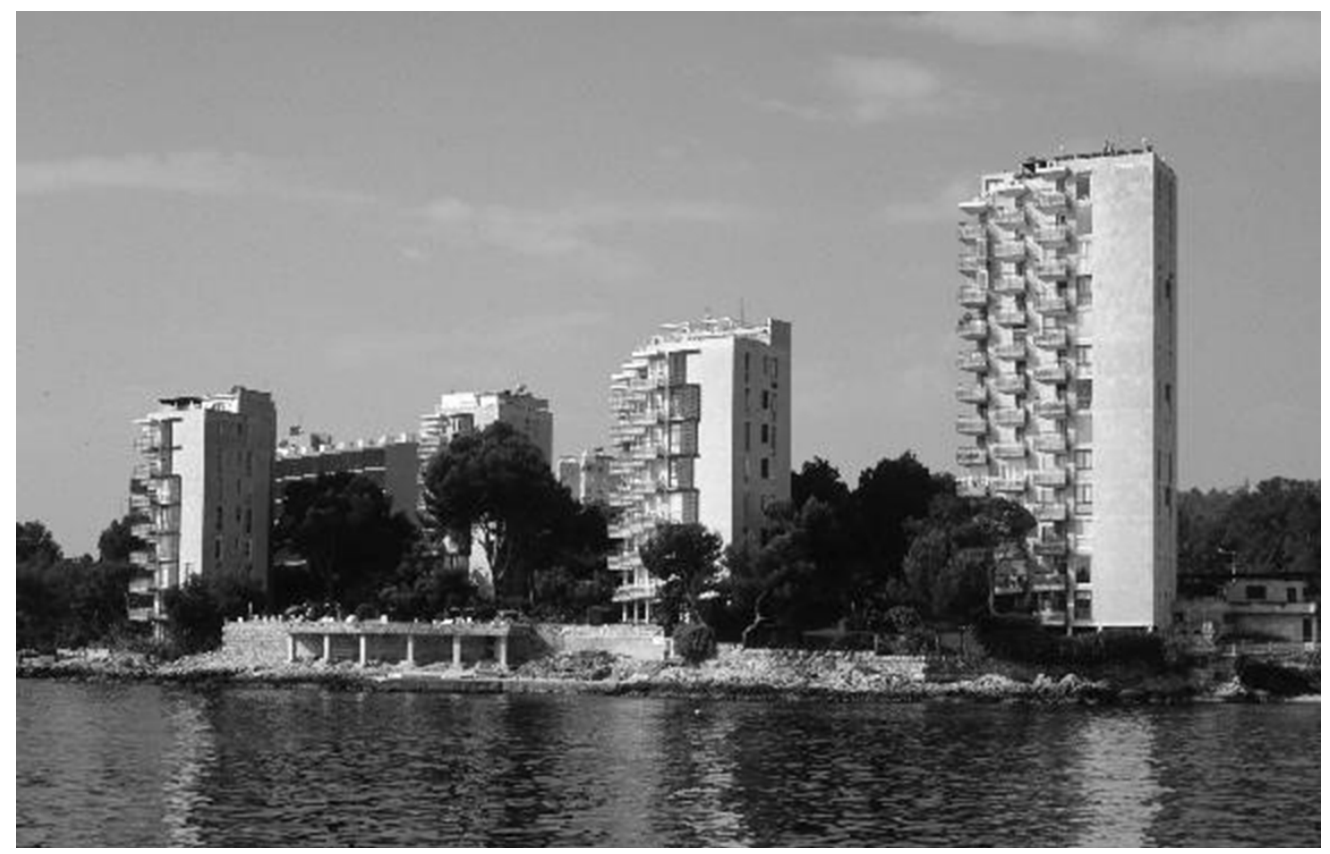

Figura 3. Conjunto Roca Marina.

- Edificios bioclimáticos desde su concepción (O’Donnel 34, Génova 27 (Figura 4), Viviendas en $\mathrm{P}^{\circ}$ Castellana, etc).

- La importancia de la estructura como elemento configurador de la arquitectura (Torres Colón, La Pirámide (7), Conjunto Galaxia , El Bernabéu).

- La revalorización de la planta baja como espacio en contacto con el peatón.

- Las fachadas que no llegan al suelo; las fachadas "plegadas" como reguladoras del medio interior (Luz, vistas, auto protección solar).

- La concepción de la " 5 a fachada", confiriendo a la cubierta de los edificios el valor integrador de oportunidad formal y funcional semejante al del resto de las fachadas.

\section{El hito de TORRES COLÓN}

Por su interés arquitectónico y técnico, la revista IdC le dedicó amplio espacio a Torres Colón (8) (9) (Figura 5), además de ser presentadas por el Instituto Torroja en el Congreso Mundial de Arquitectura y Obra Pública celebrado en Nueva York (1975), siendo considerada la obra de más avanzada tecnología en construcción edilicia hasta el momento.

Con gran profusión de datos técnicos e imágenes, en dos artículos -uno de Antonio Lamela y otro de los doctores ingenieros de Caminos, Carlos Fernández Casado, Javier Manterola y Leonardo Fernández Troyano (10)- la revista logra que la 


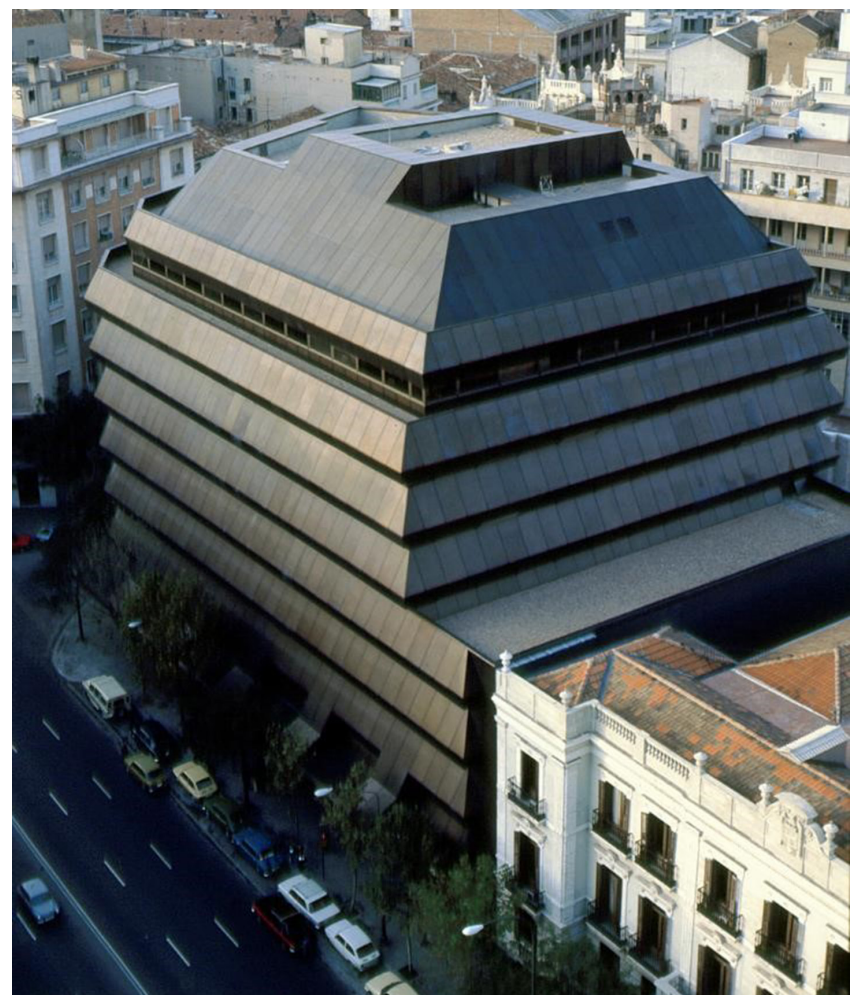

Figura 4. Edificio Génova, 27.

explicación del hito técnico no desvíe la atención de la obra arquitectónica, contribuyendo a transmitir la coherencia conceptual por la que su autor concede un especial protagonismo a la estructura, haciéndola exterior y visible para la mejor comprensión tanto de su funcionamiento como de sus elementos constructivos, pero subordinada a dos objetivos en la arquitectura resultante -diafanidad sobre y bajo rasante- y máxima esbeltez, conceptos que subyacen en la "arquitectura

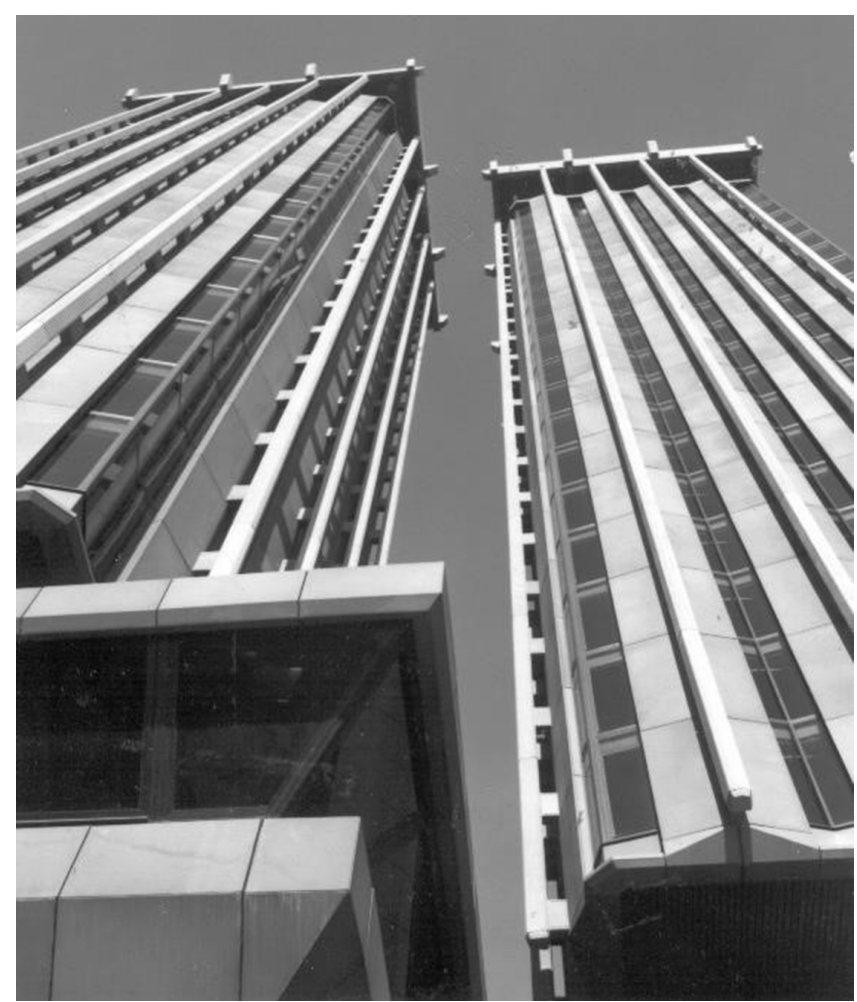

Figura 5. Torres Colón. suspendida" de las Torres. Sin olvidar la descripción del propio proceso constructivo, de arriba abajo, con la gran cimbra volada como "puente de mando", que en su descenso sirvió de singular plataforma de trabajo (8).

La excelente labor de la revista $I d C$ a lo largo de estos 70 años ha consistido en mostrar en su momento, y guardar para la Historia, la memoria de la arquitectura española e internacional, contribuyendo a generar una suerte de catálogo del patrimonio arquitectónico del siglo XX. Ahora que muchos de esos edificios se hallan en riesgo de destrucción o alteración, no está de más revisar sus páginas.

El caso de Torres Colón -la obra más emblemática de Antonio Lamela- representa un legado de innovación (8), hoy a la espera de su inclusión en el catálogo de edificios protegidos de Madrid, tal como ha dictaminado por unanimidad el Pleno del Consejo Regional de Patrimonio Histórico de la Comunidad de Madrid y que debe hacer efectivo el Ayuntamiento.

\section{Estudio Lamela, segundo ciclo}

El segundo ciclo es el de Estudio Lamela propiamente dicho, cuando se incluye el subtítulo "Urbanística y Arquitectura", pues ya la propia disciplina arquitectónica se le había quedado pequeña a AL, creando un nuevo departamento de Planificación Territorial multidisciplinar, con la colaboración de nuevos profesionales como antropólogos, sociólogos, ingenieros aeronáuticos, etc.

En estos años, posteriores a la finalización de Torres Colón, y tras su impacto mediático, el Estudio obtiene una imagen que trasciende el propio ámbito profesional de la arquitectura. Es el final del franquismo y la antesala de una grave crisis económica, debido al alza del precio del petróleo, que durará varios años. En esta época difícil el Estudio sigue innovando también en materias relacionadas con el medio ambiente, y es entonces cuando A L escribe su gran ensayo humanistacientífico: Geoísmo y Cosmoísmo como la propuesta de dos nuevas ciencias para superar el alcance del tradicional Urbanismo y empezar a pensar en regular la planificación de la Tierra y el Cosmos de forma global. A L desarrolla así el concepto de "naturalismo" como antesala de lo que al cabo de unos años sería la Ecología y la Sostenibilidad (5), conceptos y términos que hoy parece que llevan con nosotros toda la vida.

La labor profesional de A L se ve ampliada por otras actividades profesionales paralelas como la fundación de las fábricas de hormigones pre amasados "Prebetong" o la firma consultora ADI, Arquitectura, Decoración e Ingeniería para dar respuesta a proyectos internacionales en cualquier lugar del mundo con una asociación de los mejores profesionales en cada campo.

\section{Estudio Lamela, tercer ciclo}

El tercer ciclo, como parte subsecuente de Estudio Lamela, se inicia cuando yo me incorporo realmente a su disciplina, a mediados de los años ochenta y una vez finalizadas mis maestrías de postgrado en Italia.

En esta época se realiza la importante obra de la remodelación y ampliación del Estadio Santiago Bernabéu del Real Madrid, extraordinaria obra en su momento por su gran 
dificultad técnica y logística, ya que se trataba de construir, con la mínima inversión posible, -de hecho se aprovechó una parte importante de la cubierta preexistente- un nuevo graderío para 20.00o nuevos espectadores en el Estadio existente, todo ello sin perder ni una sola localidad ni un sólo día de partido durante los tres años de duración del proceso, y edificando la propia estructura sobre puntos tan complejos como el túnel del enlace ferroviario Atocha-Chamartín que discurre de forma muy somera, a pocos centímetros de profundidad del césped.

En cualquier caso son años de dificultad para la Arquitectura española, con crisis y períodos más estables que van sucediéndose de forma intermitente.

\section{LA T4 Y OBRAS ACTUALES}

\section{La Terminal T4 de Madrid Barajas}

El proyecto de la T4 supuso un "antes y un después" para Estudio Lamela, ya que permitió desarrollar una nueva escala de proyectos (11) y entrar en el reducido grupo de los estudios de Arquitectura que pueden diseñar terminales aeroportuarias.

Cuando se acercaban los importantes eventos de 1992 -los Juegos Olímpicos de Barcelona y la Exposición Universal de Sevilla- el diseño de los aeropuertos, que dependían entonces inicialmente de las Instituciones Militares y posteriormente del Ministerio de Transportes, se reorganizó para que los proyectos de esas estratégicas instalaciones, imprescindibles para aquellos acontecimientos, pudiesen encargarse directa- mente a diferentes arquitectos prestigiosos y conocidos fuera de nuestras fronteras. A Ricardo Bofill se le encomendaron las nuevas terminales de Barcelona y Málaga, a Rafael Moneo la de Sevilla y la nueva de Bilbao, a Santiago Calatrava.

Quedaba pendiente la ampliación del Aeropuerto de MadridBarajas, y tras pensar en un posible encargo directo a alguna gran figura internacional de la Arquitectura, se optó por convocar un concurso internacional en 1996.

Acudieron más de veinte propuestas, y nosotros decidimos, al no contar aún con ninguna experiencia en este tipo de proyectos, contactar con Richard Rogers, que aunque no tenía tanta experiencia aeroportuaria, había realizado recientemente el Europier de Heathrow y contaba ya con el encargo de la T5 de dicho aeropuerto. Tuvimos la fortuna de ser finalmente los adjudicatarios del proyecto en octubre de 1997, con una propuesta muy clara y rotunda, que supuso a la larga una gran innovación en el mundo de las terminales aeroportuarias. Nuestro modelo continuaba el modelo desarrollado por Foster en Stansted unos años antes, que fue también una revolución en su momento, al prescindir de instalaciones en cubierta, y plantear todos los servicios desde "abajo hacia arriba”. Esto permitió en nuestro proyecto una cubierta muy ligera y continua (12), a modo de "alfombra voladora" y situada a un mismo nivel, mientras todos los demás elementos se disponían bajo ella a diferentes alturas. Su gran flexibilidad, transparencia, facilidad de orientación para el pasajero, e incluso su tratamiento cromático en el largo dique fueron muy impactantes en su momento, así como el singular revestimiento interior de madera de bambú para la cubierta, que hoy es una de sus señas de identidad (Figura 6).

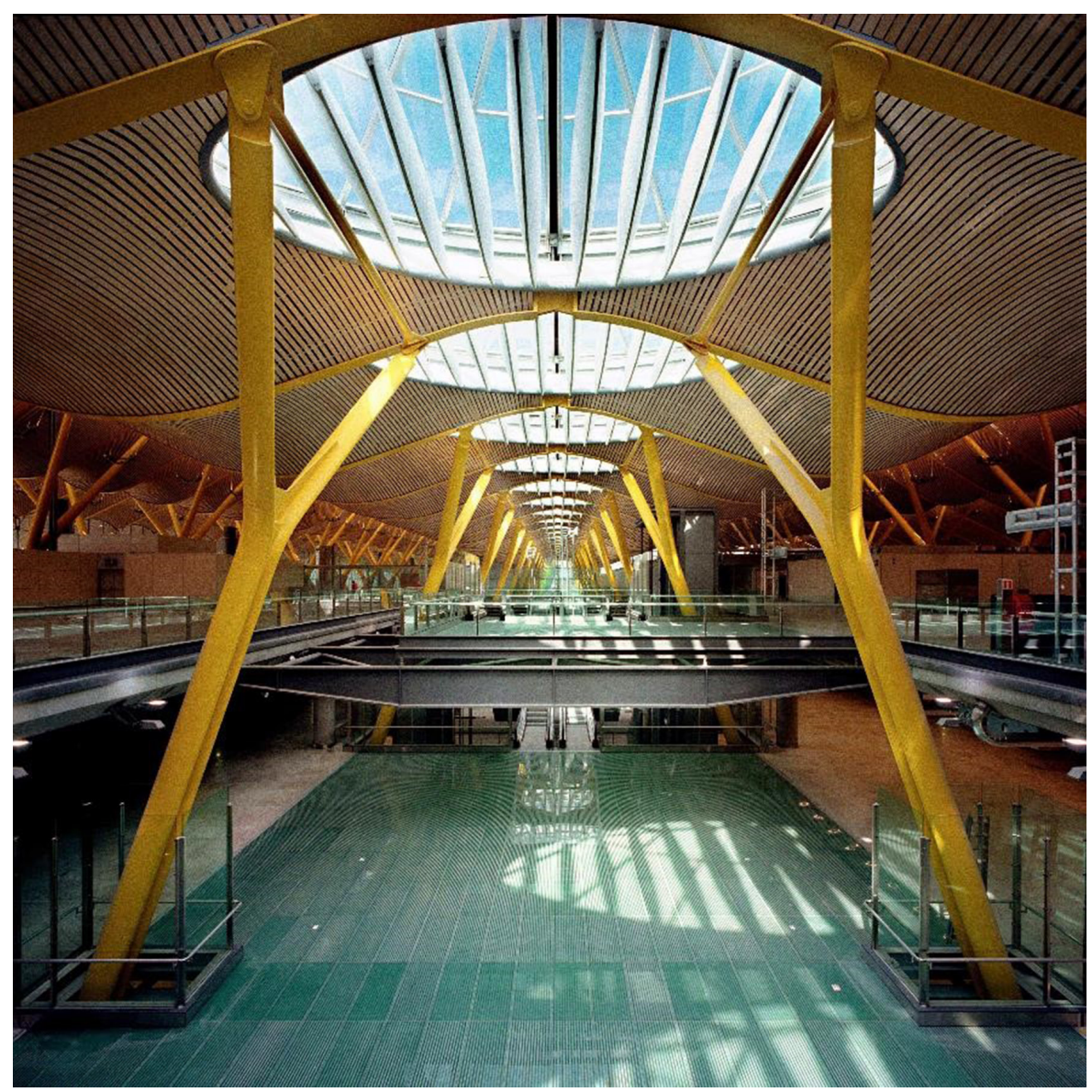

Figura 6. Terminal T4. 


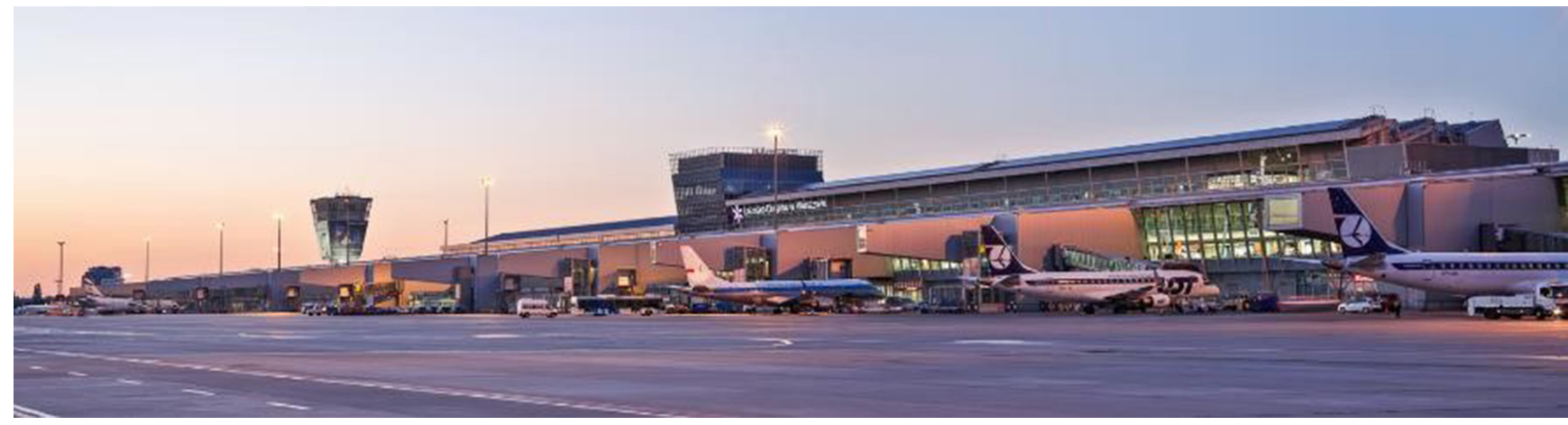

Figura 7. Terminal del aeropuerto de Varsovia.

Ha sido una de las terminales más premiadas internacionalmente en los últimos años por su diseño, y hoy es considerada como una indudable referencia en el ámbito de los aeropuertos. El prestigio derivado del proyecto, así como su impecable puesta en servicio en 2006, nos permitió acceder también a proyectar posteriormente un buen número de terminales aeroportuarias en todo el mundo y construir las dos nuevas del Aeropuerto de Varsovia, la Nueva Terminal de Tijuana en México, la reciente ampliación del Aeropuerto de Gran Canaria, así como ganar recientemente el Concurso para la Nueva Terminal de Ámsterdam-Schiphol, primer aeropuerto de Europa Continental, en unión con nuestros socios de Kaan Architekten.

En estos momentos Estudio Lamela se encuentra, además, licitando importantes terminales aeroportuarias en todo el mundo, como Praga, Jamaica, Toronto, Dammam en Arabia Saudí o Chicago.

\section{La expansión internacional}

Otra gran expresión de la innovación para un Estudio español es la mundialización de su actividad, nada fácil por nuestras tradicionales carencias como país, ya que hoy el mundo global es predominantemente sajón, tanto en sus sistemas, como en los aspectos culturales, económicos e idiomáticos.

Mi padre ya pensó durante la primera crisis del petróleo, mediados los años setenta del siglo pasado, que para mantener un estudio líder en España y de gran tamaño, era imprescindible salir fuera de nuestras fronteras y poder realizar proyectos de forma global. Pero esto, hace más de cuarenta años, no era fácil. Aún se trabajaba con lápiz y papel, sin teléfonos móviles y ni siquiera fax, que llegó diez años más tarde; con unos costes de viajes y comunicaciones muy elevados.

A pesar de ello, con mucho esfuerzo, el Estudio realizó varios proyectos de interés en América, destino natural entonces debido al idioma, construyendo alguno de ellos en Venezuela y Ecuador y destacando el "Condominio Laroc" en la ciudad de Miami.

Para un arquitecto español, ver un edificio importante construido en Estados Unidos no era fácil, y con los medios de entonces, el mérito era aún mayor.

Esta filosofía quedó insertada en el ADN del Estudio, y aunque hubo que abandonar las incursiones internacionales por sus altos costes debido a las diferentes crisis económicas que se iban sucediendo, fue fácil volver a retomarlas unos años después cuando llegó la ocasión y Estudio Lamela tuvo la madurez y robustez necesaria para ello.

De la mano de las grandes empresas constructoras, históricamente muy activas en el mercado internacional, y gracias a la experiencia adquirida en el sector aeroportuario, se presentaron ocasiones fructíferas como el concurso para la Nueva Terminal del Aeropuerto de Varsovia, en 1999, que E L ganó junto a Ferrovial, siendo posteriormente adjudicatarios de la reforma de la Terminal adjunta preexistente, completando así un proceso de más de 15 años (Figura 7). El trabajo desarrollado supuso la ocasión para establecer oficina en Polonia y construir en ese gran país importantes proyectos como los Estadios de Cracovia (Figura 8) y Lublin (Figura 9), además de singulares edificios tanto de oficinas como residenciales.

La apertura de la oficina de México se debe a que en 2005 el Estudio recibe una invitación del Banco Santander para un importante proyecto de un "Contact Center" en la ciudad de Querétaro con un programa de dos mil posiciones de trabajo y dos mil plazas de estacionamiento. Con la premisa de que el proyecto supusiese un "antes y un después" en esta tipología arquitectónica, se convirtió en el mejor edificio en su género en el mundo. Tras ganar el concurso, construido el edificio,

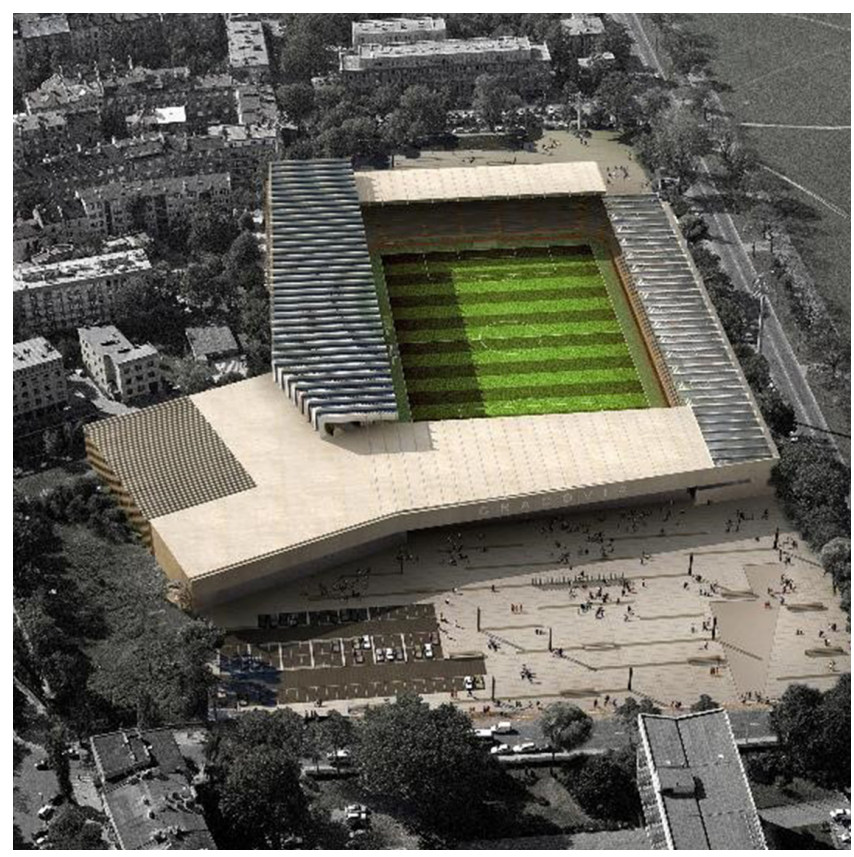

Figura 8. Estadio de Cracovia. 


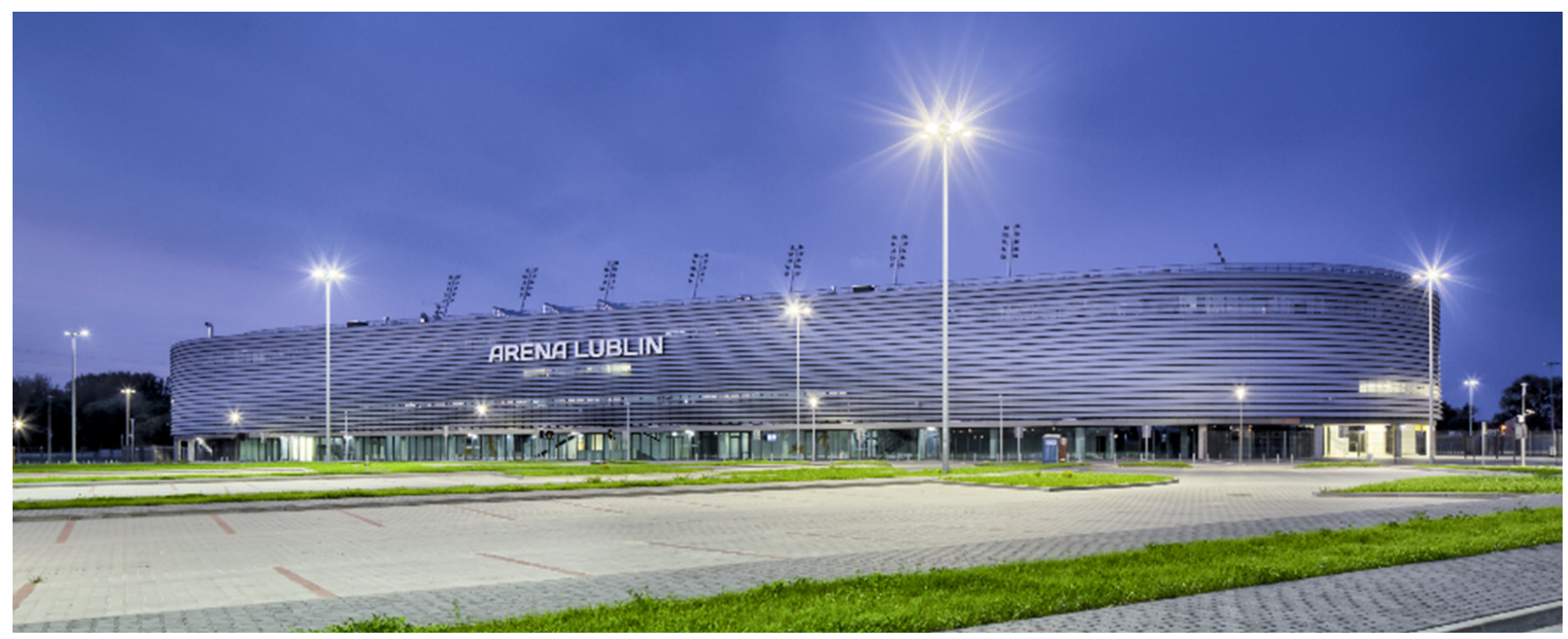

Figura 9. Estadio de Lublin.

éste se hizo acreedor de numerosos premios y hoy está considerado no solamente uno de los edificios más importantes de la reciente arquitectura mexicana, sino un preciado emblema tanto para la ciudad de Querétaro como para el Banco Santander (Figura 10).

Este hecho permitió asentar nuestra oficina en la Ciudad de México, donde en los últimos años, bajo el nombre de Estudio Lamela o de nuestra empresa asociada LAM Arquitectos, hemos desarrollado interesantes proyectos residenciales y de todo tipo.

Nuestra expansión internacional ha continuado con el establecimiento de oficinas en Oriente Medio, donde hemos realizado importantes proyectos como la "Torre Marina Mix" en Doha, con cuarenta niveles, o las siete estaciones del Metro Ligero de Lusail.

También, en África Central, en Guinea Ecuatorial, donde se proyectaron las nuevas terminales aeroportuarias de Mala- bo, Bata y Mongomeyén correspondientes a un Plan de Aeropuertos encargado por el Gobierno Ecuatoguineano.

Durante estos años también se exploró el desarrollo de proyectos en Shangai o São Paulo, ciudades en las que tuvimos oficina estable durante varios años, pero donde las especiales circunstancias de cada país no siempre permiten encontrar los cauces adecuados para realizar proyectos de suficiente envergadura que rentabilicen las necesarias inversiones.

Desde la oficina de Madrid se han acometido interesantes proyectos de forma puntual en muy diversos países, algunos ya construidos como el Hospital de Veraguas en Panamá, o la reforma de reestructuración completa de la emblemática "Torre Astro" de Bruselas (Figura 11), que con sus treinta y tres plantas es uno de los edificios más representativos de la capital belga y ha obtenido la distinción de ser la primera gran torre europea con el sello de edificio pasivo, consumiendo menos energía de la que genera.

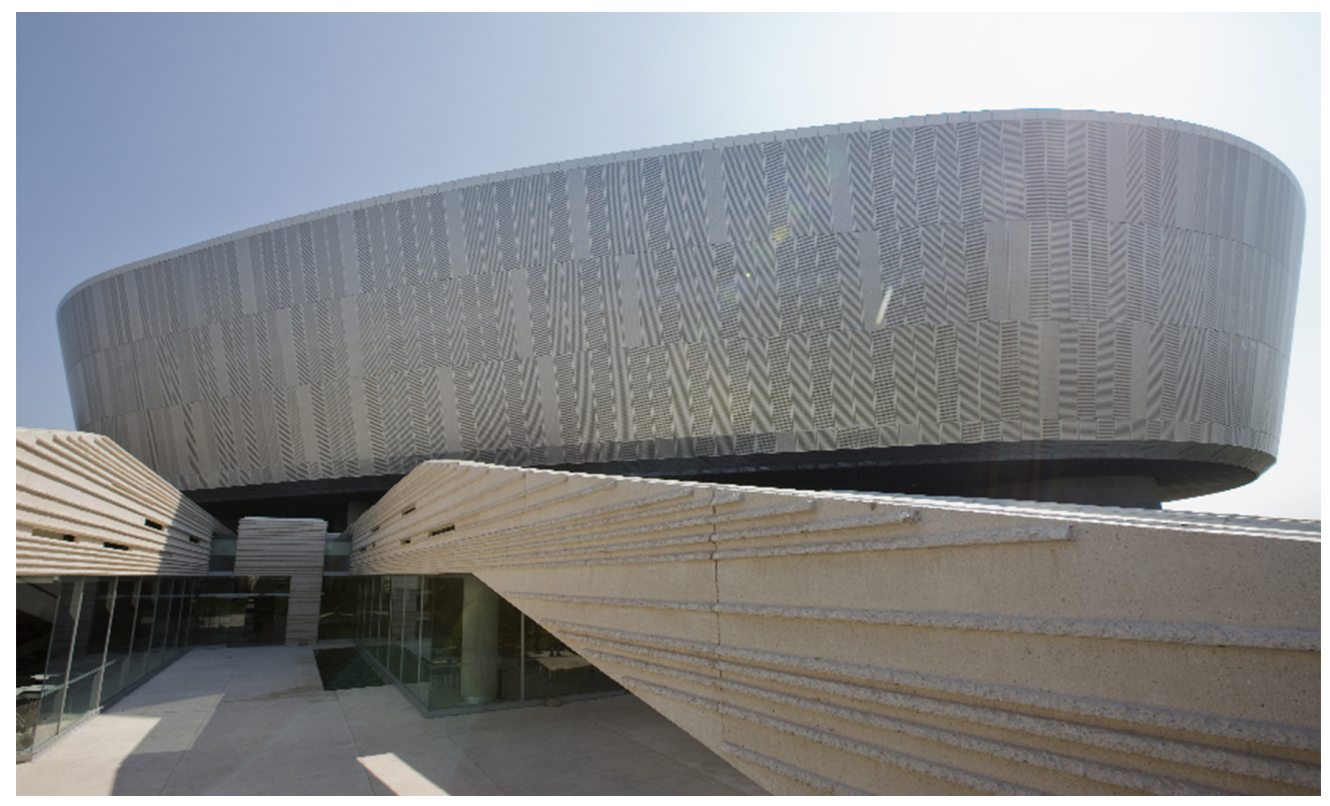

Figura 10. “Contact Center” del Banco Santander en Querétaro. 


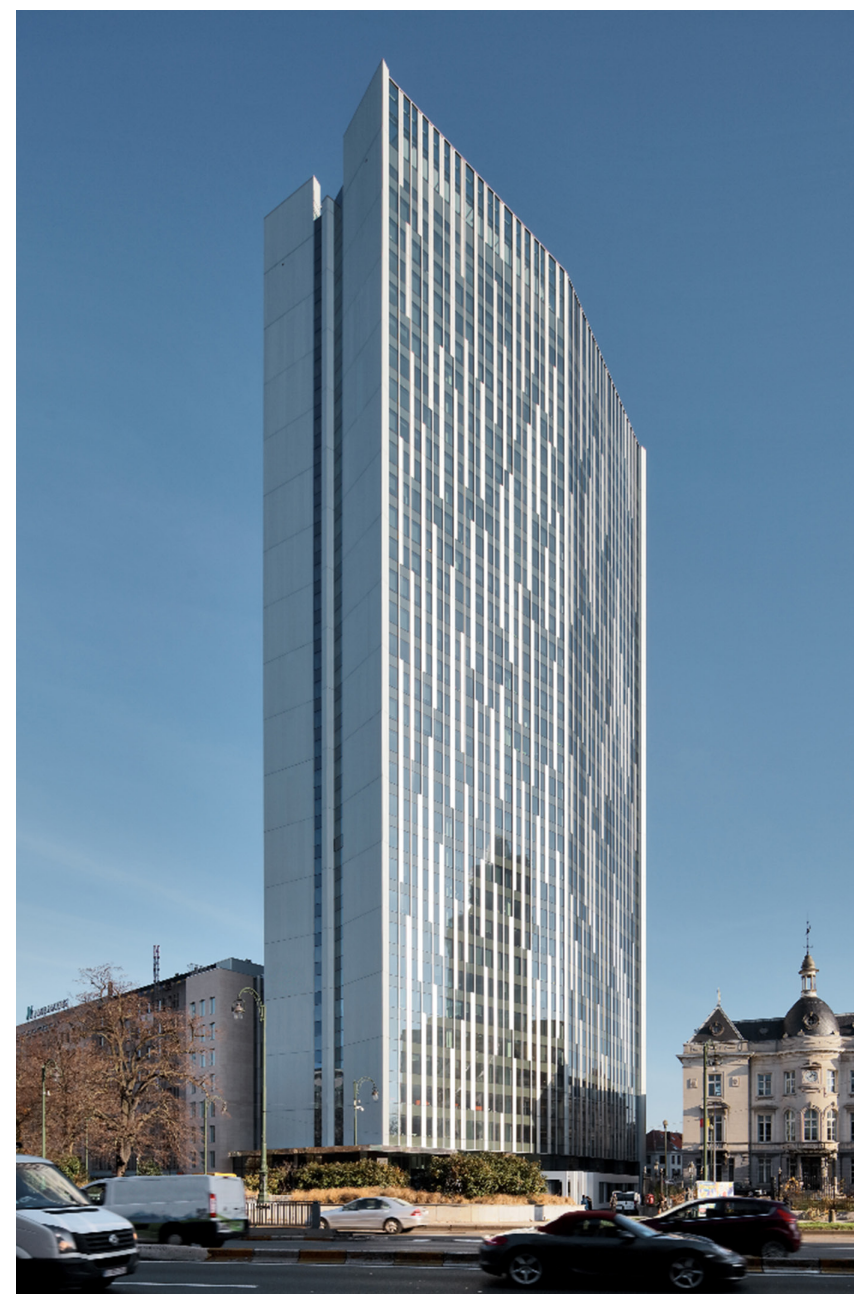

Figura 11. Torre Astro en Bruselas.

\section{Los proyectos recientes en España durante la última década}

A pesar de la reciente crisis, que ha durado casi diez años, mucho más de lo que podíamos prever en sus inicios, se han desarrollado importantes proyectos en nuestro país, la mayoría en el ámbito residencial y de oficinas, donde destacan las sedes de John Deere y Caja Badajoz (Figura 12), el edificio universitario de Imdea, o el recientemente terminado Discovery para Colonial (Figura 13), que ha alcanzado varías distinciones, entre ellas el contar con uno de los pocos sellos Leed Platinum en la ciudad de Madrid.

En los próximos meses veremos finalizar las obras del gran Complejo Canalejas, en pleno corazón de Madrid, actuación complejísima en sus aspectos técnicos y logísticos, que se convertirá en el nuevo Hotel "Four Seasons", probablemente el mejor gran establecimiento hotelero construido en la historia de la capital, al contar con doscientas habitaciones y una galería comercial del máximo nivel, así como con las más de veinte residencias de gran lujo asociadas que coronarán su perfil.

Esta obra ha sido desarrollada con los métodos más modernos y novedosos para poder realizar un nuevo edificio con todos los adelantos y comodidades, pero manteniendo las fachadas y crujías preexistentes determinadas por las ordenanzas. Su sistema constructivo bajo rasante ha contado con las más avanzadas técnicas desarrolladas en el mundo en actuaciones de este tipo.

Con el nuevo gran Campus de oficinas y servicios para la multinacional Airbus que va a desarrollarse en Getafe, en las proximidades de la capital, y otros importantes complejos de oficinas y edificios de viviendas que estamos proyectando actualmente o van a iniciarse próximamente, Estudio Lamela mira al futuro con gran optimismo, pero apoyándose en su

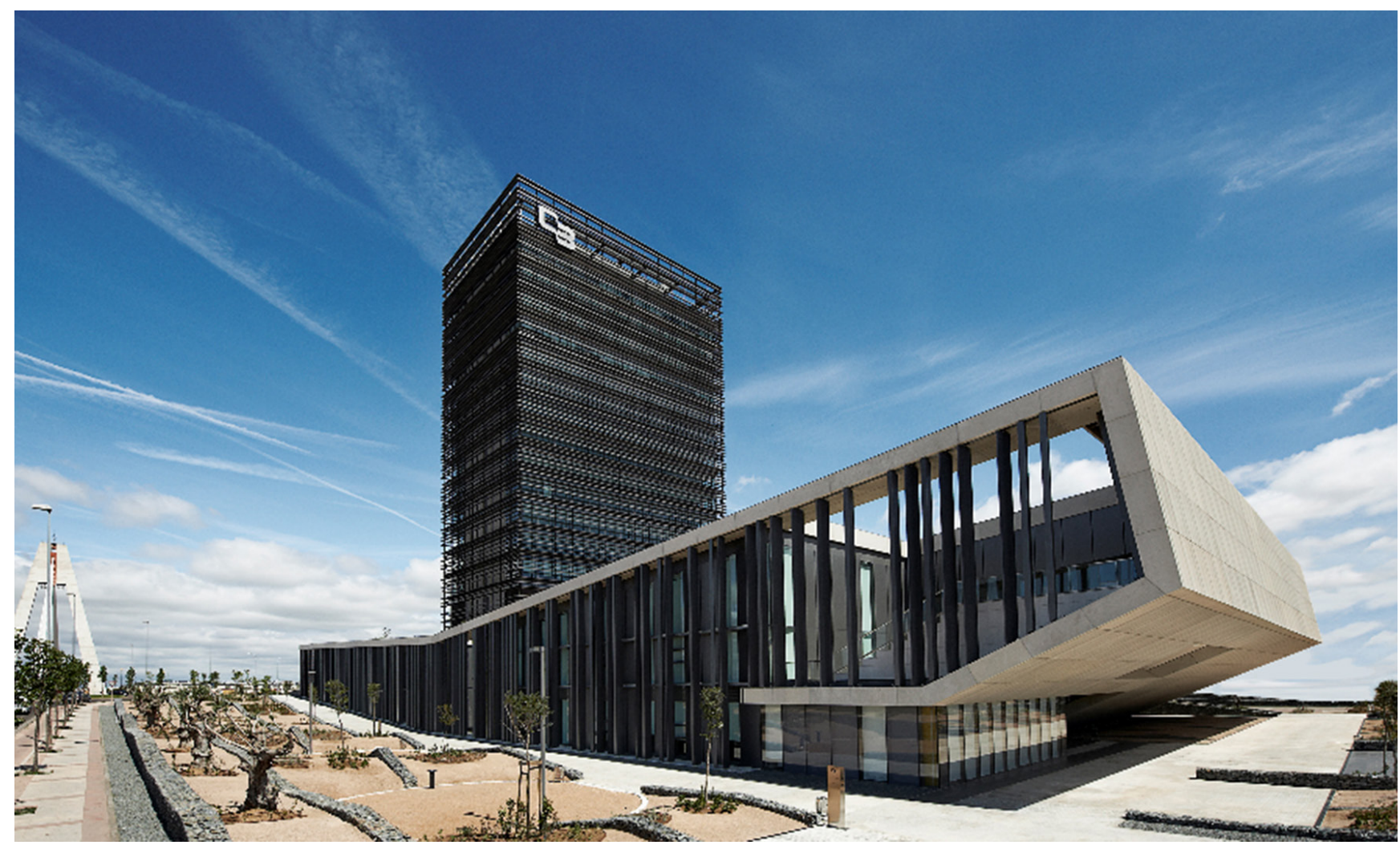

Figura 12. Sede de Caja Badajoz. 


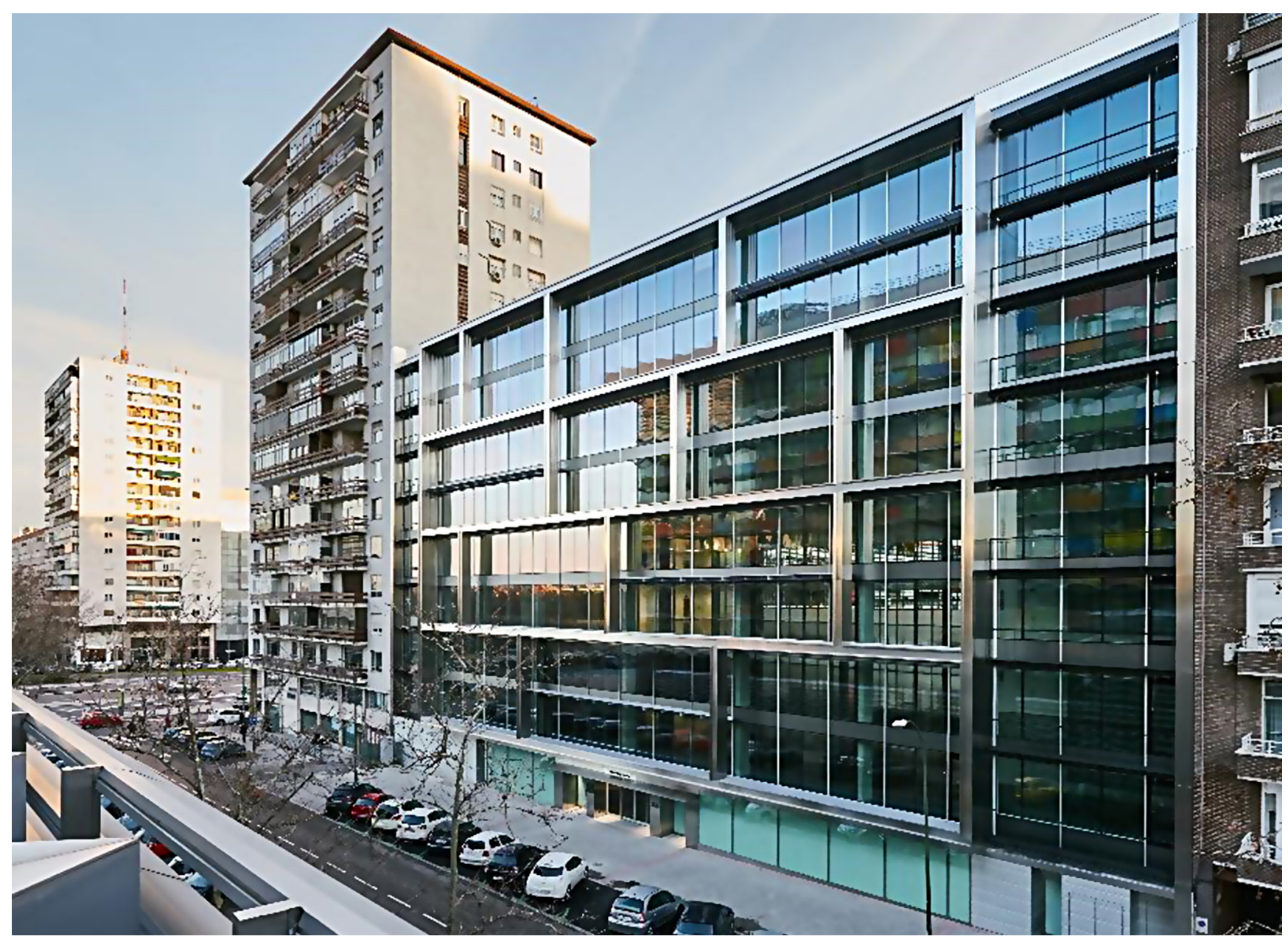

Figura 13. Edificio Discovery para Colonial.

singular pasado, muy comprometido con la historia constructiva y arquitectónica de nuestra gran Nación. A esa historia ha contribuido nuestra querida revista Informes de la construcción, mostrando lo que se hacía, no sólo en España sino también en el resto del mundo, a través de miles de proyectos.
Esperemos que dentro de por lo menos otros setenta años, podamos celebrar su casi siglo y medio de existencia, pero quizá también a través del análisis de proyectos realizados en el Cosmos, tal como habría deseado, con su espíritu visionario, mi padre.

\section{REFERENCIAS}

(1) Cassinello, P., Cassinello, N., 2018. ANTONIO LAMELA - más allá de la innovación In Memoriam. Inf. Constr. 69 , e234. https://doi.org/10.3989/id.59961

(2) Oteiza, I., Azorín López, V., Salas Serrano, J., 2008. “Informes de la Construcción”: past, present and future. Inf. Constr. 6o. https://doi.org/10.3989/ic.2008.v6o.i510.736

(3) Lamela, A., 1958. Viviendas y oficinas. O’Donnell, 33, Madrid. Inf. Constr. 11, 33-48. https://doi.org/10.3989/ic.1958. v11.i106.5459

(4) Lamela, A., 1960. Motel El Hidalgo. Inf. Constr. 13, 43-54. https://doi.org/10.3989/ic.1960.v13.1126.5125

(5) Lamela, A., 2005. Sustainability, an inescapable global challenge. Inf. Constr. 57. https://doi.org/10.3989/ic.2005.v57. i $499-500.482$

(6) Lamela, A., 1967. 2 Obras de A. Lamela: Edificios Sol y La Caleta en Palma de Mallorca. Inf. Constr. 20, 13-34. https:// doi.org/10.3989/ic.1967.v20.i195.3966

(7) Lamela, A., 1980. Pirámide de oficinas y locales comerciales Madrid - España. Inf. Constr. 33, 13-24. https://doi. org/10.3989/ic.1980.v33.i321.2306

(8) Lamela, A., 1977. Torres Colón Madrid - España. Inf. Constr. 30, 29-54. https://doi.org/10.3989/ic.1977.v30.i293.2643

(9) Blanco, P.J., Buzón, R., 1970. Edificios Colgados. Inf. Constr. 22, 45-67. https://doi.org/10.3989/ic.1970.v22.i219.3581

(10) Fernández Casado, C., Manterola, J., Fernández Troyano, L., 1977. Estructura de las Torres Colón - Madrid - España. Inf. Constr. 30, 61-94. https://doi.org/10.3989/ic.1977.v30.i293.2644

(11) Lamela, A., 2006. New Terminal Area of the Madrid-Barajas airport T-4. Inf. Constr. 58. https://doi.org/10.3989/ ic.2006.v58.i501.395

(12) Lamela, C., 2002. New terminal area for Madrid-Barajas airport. Inf. Constr. 54. https://doi.org/10.3989/ic.2002.v54. i 479.616 